\title{
The Civic Footprints of Labor Market Participation: Longitudinal Evidence from the United States, 2002-2015
}

\author{
Dingeman Wiertz \& Chaeyoon Lim
}

(Social Forces)

\begin{abstract}
While there is a widespread belief that stable employment is important for social integration, stable employment careers have become less common in America's increasingly complex labor market. Job tenure has dropped, precarious work arrangements have gained prominence, longterm unemployment has spiked, and an increasing share of the jobless are not looking for work. Against this background, we investigate the linkages between labor market experiences and volunteer activities, as indicator of people's involvement in civic life. We outline a theory on how transitions between labor market states — within, into, and out of the labor force-bring about changes in civic engagement and test our predictions using panel data from the Current Population Survey 2002-2015. Contrary to what much previous research suggests, we find that people who become unemployed are more likely to start volunteering and no more likely to stop. We additionally show that people who leave the labor force altogether (i.e., not having a job nor looking for one) are more likely to stop volunteering. Conversely, entering the labor force, either by securing or searching for a job, is associated with an increase in volunteer activities. We explore the role of motivation and time resources in accounting for these patterns, finding among other things that moving into or out of the most detached labor market stateoutside the labor force without any intention to find work-is most consequential for civic engagement. We discuss the implications of our findings for civic democracy in light of ongoing labor market trends.
\end{abstract}




\section{Introduction}

Sociologists have long suggested that employment plays a key role for social integration. Aside from being a source of income, employment offers "latent benefits" that include workplace contacts, a sense of purpose and identity, and social status (Jahoda 1982). The flip side is that a lack of stable employment puts individuals at risk of social exclusion (Gundert and Hohendanner 2014; Rotolo and Wilson 2003). What is more, a widespread shortfall of stable employment may undermine the social fabric that holds together communities (Jahoda, Lazarsfeld, and Zeisel 2002[1933]; Lim and Laurence 2015).

From this perspective, several ongoing labor market trends in the United States provide cause for concern. To begin with, labor force participation has shrunk considerably over the past decades. While this is partially driven by population aging and young adults staying longer in education, decreases in labor demand due to globalization and automation have also contributed (Abraham and Kearney 2018). Nowadays, nearly 20 percent of the prime working-age (25-54) population neither has a job nor is looking for one and the labor force participation rate among prime-age men is now the second-lowest within the OECD (Council of Economic Advisers 2016; Krueger 2017). Moreover, job tenure has dropped significantly (Hollister and Smith 2014), and nonstandard work arrangements and contingent contracts have gained prominence (Kalleberg 2011). On top of these developments, there is the labor market turmoil stirred up by the Great Recession. Long-term unemployment, for instance, quadrupled to four percent during the recession and has only been slowly coming down since (Kroft et al. 2016).

With these trends in mind, we examine how labor market experiences influence engagement in civic activities, especially volunteer work. High levels of civic engagement are regarded as a cornerstone of American society and have been linked to improved health, labor market rewards, and social cohesion (e.g., Borgonovi 2008; Putnam 2000; Ruiter and De Graaf 2009). In turn, civic participation is believed to be tightly connected to employment or even to be a "natural extension of participation in the labor market" (Wilensky 1961:522).

Several studies have addressed how the economic and civic domains are linked, often focusing on the impact of unemployment on civic engagement (e.g., Clark and Heath 2014; Lim and Sander 2013; Musick and Wilson 2008). However, unemployment alone fails to capture the full range of disruptions that people can experience on the labor market. This is particularly true 
given the declines in labor force participation and employment stability as well as the rise of precarious labor. The labor market can thus no longer be adequately described as a dichotomy of people with and without jobs. Among the employed secure full-time jobs are no longer the norm and there is also increased diversity among the jobless in terms of their employment history, reasons for not having a job, and desires to find work.

This study extends the literature by analyzing how a wide range of labor market experiences influence civic participation. We argue that each labor market state offers a unique mix of motivations, resources, and opportunities to take part in civic life. Transitions between labor market states can consequently pull people into civic life or push them out of it. Since the precise combination of labor market origin and destination will be key, solely looking at the civic effects of being or becoming unemployed provides only limited insights. We, therefore, apply a broader analytical focus - distinguishing a variety of transitions within, into, and out of the labor force - which will illuminate how ongoing labor market trends may affect American civic life.

Examining the civic footprints of a wider variety of labor market experiences will also help to unpack the mechanisms underlying the links between the economic and civic domains. In this context, the literature on civic participation emphasizes several factors-including motivation, resources, and social networks-that can shape involvement in civic life (Hustinx, Cnaan, and Handy 2010; Musick and Wilson 2008; Verba, Schlozman, and Brady 1995; Wilson 2000). Yet, it is difficult to study their interplay when comparing only employment versus unemployment. By instead investigating a wider array of labor market transitions, we have more leverage to identify how these factors jointly shape civic participation.

While much previous research has focused on the static relationships between labor market states and civic participation, we adopt a dynamic approach and ask how labor market transitions are linked to changes in civic behavior. Hence, we can take both labor market origins and destinations into account and investigate how the labor market pathways that people follow influence their civic behavior. Our dynamic approach also enables us to separately examine movements into and out of certain labor market states, instead of assuming that their civic effects are symmetrical. 
In the remainder of the paper, we first outline our theory on how moves toward stronger or weaker labor market integration bring about changes in civic participation. We next turn to panel data from the Current Population Survey for the 2002-2015 period to test our predictions. Our analysis yields novel findings that qualify previous insights and illuminate the social processes underlying the nexus between the labor market and civic life. By broadening the scope of investigation and adopting a dynamic approach, this study deepens our knowledge of how labor market experiences shape civic engagement and, more generally, how labor market experiences can have spillover effects into other life domains.

\section{Labor market participation and civic engagement}

In this section, we develop the analytical framework that underpins our hypotheses. We start with a brief literature review, as background to our analytical approach.

\subsection{Review of previous studies}

Previous studies have often focused on the impact of unemployment on civic activities. In this literature, there are two conflicting schools of thought. The first conceptualizes civic activities as a consumption or investment good, and contends that unemployment stimulates civic engagement. The idea is that for the unemployed civic participation entails lower opportunity costs than for the employed (Freeman 1997) and provides opportunities to consolidate résumés, build connections, and develop work-related skills (Prouteau and Wolff 2006; Spera et al. 2015).

The second and more prominent perspective rejects these optimistic views and asserts that unemployment depresses civic participation. Proponents of this view consider civic activities an "expression of community belonging and group identity" (Hustinx et al. 2010:417), rather than a consumption or investment good. To understand the link between unemployment and civic engagement, they draw on the critical role that stable employment plays for social integration (Jahoda 1982; Rotolo and Wilson 2003; Wilensky 1961). Accordingly, unemployment would lead to weaker social integration and disengagement from civic activities by impairing people's economic and social resources, diminishing their exposure to civic opportunities, weakening their sense of belonging and purpose, and evoking feelings of shame and self-blame (Brand 2015; Chen 2015; Gundert and Hohedanner 2014). This may especially apply in the United States, as American republican culture makes "citizenship conditional on 
self-sufficiency and production" (Lamont 2000:52). In such an environment, job loss can be particularly damaging to one's self-respect and sense of membership in society (Chen 2015).

In light of these opposing views, the empirical evidence on the civic impacts of unemployment remains inconclusive (Brand 2015). Most evidence comes from cross-sectional studies that compare civic participation levels between the employed and the unemployed. These studies generally find that the unemployed are civically less active (e.g., Clark and Heath 2014; Lim and Sander 2013; Musick and Wilson 2008). These findings do not tell us much about causality, however, as it remains unclear whether the unemployed give up their civic activities upon becoming unemployed or whether they were already less active before. Moreover, it matters how the reference group is defined. For example, Piatak (2016) concludes that, after adjusting for sociodemographic factors, the unemployed are more likely to volunteer than full-time workers but less likely than part-time workers. Similarly, factors such as self-employment and employment sector give rise to further heterogeneity among the employed (Musick and Wilson 2008) and other evidence suggests that the influence of unemployment may differ by gender (Taniguchi 2006).

Longitudinal studies on this topic are scarce and their findings mixed. In line with most crosssectional evidence, a few European studies find that people withdraw from civic activities after becoming unemployed (Erlinghagen 2000; Strauß 2008). Likewise, Brand and Burgard (2008) use the Wisconsin Longitudinal Study to show that job displacement has long-term repercussions for social participation. By contrast, analyzing the German Socio-Economic Panel, Lancee and Radl (2014) find no clear evidence that unemployment is detrimental to civic engagement. Although they find that unemployed individuals volunteer less frequently than do the employed, the effect of becoming unemployed is close to zero.

Aside from these mixed findings, it remains unclear how factors such as resources and motivations complement and compete with each other in driving the relationships between labor market experiences and participation in civic life. For instance, if unemployment undermines civic participation, to what degree does this reflect a loss of social connections or rather a weakened sense of social membership and purpose? Further, to what extent are such gaps attenuated by the fact that the unemployed may have more time available and stronger incentives to take up civic activities? Most previous research offers limited insight into these questions. 
This is partly due to the narrow focus on a single labor market state, namely, unemployment. Moreover, unemployment is often defined broadly and measured as a self-identified status. Consequently, the "unemployed" in previous studies can be highly diverse, encompassing labor force outsiders such as passive job-seekers and discouraged workers. In addition, previous studies focus on variation in civic participation among different labor market states. This makes it more difficult to investigate the mechanisms linking labor market experiences and civic engagement. Static analyses also ignore that the civic effects of being in a certain labor market state may hinge on the state one was in before and that the influence of, say, entering and exiting employment may be non-symmetrical. These limitations would be less problematic if labor market status and civic participation were highly persistent over time, with people rarely experiencing transitions. This, however, is becoming less and less common in the "age of precarious labor" (Kalleberg 2011).

\subsection{Labor market integration and civic engagement through a dynamic lens}

We propose a dynamic analytical framework that views labor market transitions as key events of interest. Our framework assumes that different labor market states represent varying levels of labor market integration, with employment corresponding to the strongest degree of integration, followed by unemployment (i.e., jobless but actively searching for a job), and finally being outside the labor force (i.e., having no job nor looking for one). Transitions between these states trigger changes in civic participation by shaping individuals' motivation, resources, and opportunities for civic action. We distinguish between the starting and stopping of civic activities, since becoming and staying involved (or uninvolved) are distinct processes with potentially different drivers (Rotolo 2000).

Our starting assumption is that every individual has their own baseline propensity to engage in civic activities, influenced by early-life socialization processes and factors such as educational attainment and religiosity. This baseline propensity will remain largely stable among adultsat least in the short run-unless they experience major shifts in their life circumstances. We therefore predict that the rates of quitting civic activities among "joiners" and starting civic activities among "non-joiners" are relatively low at any point in time. 
Nevertheless, significant life events such as family formation, childbearing, and residential relocation can disrupt this equilibrium. We suggest that a change in labor market status is another such event, which can influence people's motivation, resources, and opportunities to participate in civic life, as the core drivers of civic engagement. The "Civic Voluntarism Model" proposed by Verba and colleagues (1995) argues in this context that civic participation is shaped by whether one wants, is able, and is asked to participate. Musick and Wilson (2008) apply a similar distinction, between "subjective dispositions", "individual resources", and "social context". Building on these theoretical traditions and adding a further distinction between intrinsic and instrumental motives, our analytical framework considers four factors that can shape civic engagement decisions.

First, labor market transitions can affect people's feelings of social membership, which give them a sense of purpose and self-esteem, and thus motivate and empower them to engage in civic activities. Furthermore, some transitions can influence people's instrumental incentives to take part in civic life, making them more eager to build connections and develop skills through civic engagement. The underlying idea is that civic activities can be instrumental to one's career, helping people to improve their employability and get ahead on the labor market. Additionally, labor market transitions can affect people's capability of carrying out civic activities by altering their resources (especially time resources). Lastly, they can reshape people's social connections and thereby their exposure to civic opportunities. Combining these four mechanisms, our framework represents a hybrid between subjectivist approaches to civic engagement that focus on individuals' motives and behaviorist approaches that stress cost-benefit tradeoffs given limited resources (Wilson 2000; Hustinx et al. 2010).

As we discuss below, the four mechanisms can reinforce or offset one another, depending on the labor market transition in question. Figure 1 provides a visual illustration of how we expect each factor to be related to labor market integration, holding all else equal.

\section{$\ll$ INSERT FIGURE 1 HERE $\gg>$}

\subsubsection{Transitions toward stronger labor market integration}

In general, we expect that when individuals integrate further into the labor market (e.g., entering the labor force or moving from unemployment to employment), this strengthens their 
motivation to engage in civic life by boosting their sense of belonging, purpose, and efficacy.[ENDNOTE 1] Some transitions toward greater labor market integration can additionally promote work-based connections, which may expand people's exposure to civic opportunities, reinforce their sense of belonging, and offer social incentives for civic participation.

The impact of increased labor market integration on people's career-related instrumental incentives for civic engagement is more complex. Such incentives can be particularly strong for people who begin a job search or consider entering the labor force, as participation in civic activities can boost their chances of finding a job (Spera et al. 2015). On the other hand, instrumental incentives are less relevant when labor force entrants move directly into stable employment and may even weaken when moving from unemployment to a desirable job.

Some transitions toward greater labor market integration can also restrain civic engagement via curtailing free time. Taking up employment can impose especially stringent time constraints, depending on the demands of the new job. In principle, entering the labor force by launching a job search may also restrict the time available for civic activities, yet given that unemployed Americans on average devote only 41 minutes to job search on weekdays (Krueger and Mueller 2010), this is unlikely to form a serious obstacle.

On balance, transitions that strengthen individuals' integration into the labor market will usually enhance their motivation and opportunities to participate in civic life. However, when individuals take up more secure or demanding jobs, these positive effects can be offset by weaker instrumental incentives and stricter time constraints. This particularly holds when individuals previously resided at the edge of the labor market, without stable employment but actively searching for a job. Therefore, while moving from outside the labor force to unemployment will unequivocally stimulate civic participation, moving from unemployment to employment may have weaker or even negative effects.

\subsubsection{Transitions toward weaker labor market integration}

We expect that transitions that weaken people's integration into the labor market diminish their motivation to participate in civic life by undermining their sense of social membership and identity as active citizens. These effects will be strongest when people exit the labor force 
discouraged after a long and unsuccessful job search, as such exits can be especially damaging to one's sense of purpose and self-esteem. By contrast, voluntarily leaving employment or losing one's job while staying committed to finding new work will be less harmful. Yet, those moves still imply a loss of work-based social connections as intermediaries to civic activities. As a potential offset, we expect people's instrumental incentives for civic participation to intensify when they move from employment to the edge of the labor market. However, when people lose their work ambitions and stop their job search, their instrumental incentives will weaken.

When people exit employment or the labor force, this frees up time previously spent on their job or job search activities. However, it is uncertain whether this newly gained time will counterbalance any negative civic effects of their weaker labor market integration. As Jahoda and colleagues (2002[1933]:66) conclude in their Marienthal study, the extra time may prove to be a "tragic gift": "Cut off from their work and deprived of contact with the outside world, the workers of Marienthal have lost the material and moral incentives to make use of their time." In short, the civic impact of additional free time may be contingent on one's motivation to stay involved in the labor market and public life; thus, positive when one moves from employment to the margin of the labor market, yet less relevant when one leaves the labor force entirely.

In any case, people leave the labor force for various reasons and have different ways and means of coping with changing circumstances. This may give rise to divergent civic outcomes. Indeed, while paid employment represents a critical foundation for social integration, it is not the only social institution that fulfils this role. Parenthood is another prime example, offering a strong social identity and sense of purpose and keeping people connected to civic networks through schools (Taniguchi 2006; Musick and Wilson 2008). Enrollment in education can provide a similar buffer (Chen 2015). However, many labor force dropouts lack such cushions. For instance, prime-age men outside the labor force spend hardly — if any-more time on education, childrearing, or other care activities, compared to their counterparts in the labor force (Council of Economic Advisers 2016). Instead, they spend much of their extra time watching TV and playing video games (Aguiar et al. 2018) and they are more prone to opioid use (Krueger 2017). Such behaviors likely stand in the way of (continued) civic involvement. Overall, we expect that the negative civic effects of leaving the labor force are most pronounced when people have no alternative base of social membership and purpose outside the labor market. 


\subsubsection{Summary of key predictions}

1a) Moving toward stronger labor market integration generally boosts civic engagement.

1b) When people move into (full-time) employment, these positive civic effects are dampened, as instrumental incentives become weaker and/or time constraints tighter.

2a) Moving toward weaker labor market integration generally diminishes civic engagement.

2b) When people intend to return to work or when they have alternative sources of purpose and identity, these negative civic effects are dampened.

\section{Data and methods}

\subsection{Data source and sample}

We analyze data from the Current Population Survey (CPS), covering the period 2002-2015. The CPS is a monthly household survey administered by the Bureau of Labor Statistics (BLS) and it is ideal for this study. First, every September survey from 2002 to 2015 includes a supplement on volunteering and other civic activities. Second, the CPS uses detailed questions to determine respondents' labor market status according to the BLS definitions. This means that jobless individuals are classified as unemployed only if they are actively searching for work; otherwise they are counted as labor force outsiders. Third, owing to a rotating panel design, every September survey contains respondents that have already been interviewed one year earlier. This enables us to track respondents' civic participation and labor market trajectories. Fourth, large sample sizes allow for fine-grained distinctions between different labor market states and transitions. Finally, the CPS has high response rates, alleviating the non-response biases that often undermine survey research on social participation (Abraham, Helms, and Presser 2009). Over the 2002-2015 period, the average household response rate was 91 percent, with an individual response rate to the Volunteering Supplement of 87 percent among interviewed households.

Matching respondents across survey waves is not straightforward, because the CPS samples addresses rather than households and does not contain a consistent identifier for individual household members. Relying on the matching method proposed by Rivera Drew, Flood, and Warren (2014), we first match respondents across survey waves based on their household 
identifier and line numbers, and then check the matching quality using basic demographic characteristics (i.e., sex, race and age), retaining only matches with consistent traits. The resulting matching rate equals 66 percent —a respectable re-interview rate vis-à-vis other national panel surveys. In Section B of the online supplement, we investigate to what degree our results may be biased due to selective attrition. Among other things, we estimate Heckmantype selection models to correct for selective attrition based on unobservable factors. These analyses suggest that the results reported below are not sensitive to attrition bias.[ENDNOTE 2] After listwise deletion of cases with missing values, our sample comprises 348,901 individuals aged 15 or over who are each observed twice.[ENDNOTE 3]

\subsection{Dependent and independent variables}

\section{$\underline{\text { Volunteering activities }}$}

Our analyses consider whether individuals start or stop volunteering between their two interviews. For this purpose, we construct binary indicators for having done any volunteer work in the year preceding each interview, based on the following survey item: "Since September $1^{\text {st }}$ of last year, have you done any volunteer activities through or for an organization?" If respondents answer negatively, they are reminded that activities for schools or youth clubs also count. Among the civic activities covered in the CPS — which include attending public meetings to discuss community affairs and working together with neighbors to address local issuesvolunteer work is most common, and 64 percent of the people involved in the other types of civic activities are also volunteers.[ENDNOTE 4] Of all respondents, 42 percent report volunteering activities in at least one interview, but only half of them do so in both.

\section{$\underline{\text { Labor market trajectories }}$}

We distinguish three core labor market states: employment, unemployment, and not in the labor force (NILF). In line with the BLS definitions, one needs to be actively looking for work in order to be classified as unemployed. We construct binary indicators for each possible combination of labor market states between respondents' first and second interview, thus mapping their labor market trajectories. In this classification, employment represents the strongest level of labor market integration and "NILF status" the weakest. Nevertheless, within 
each category there is variation in the degree of labor market integration, some of which we will explore later on.

\section{Control variables}

All analyses adjust for the following characteristics: sex, age, race, being born in the United States, educational attainment, household income, home ownership, marital status, and parental status.[ENDNOTE 5] These factors-measured at the first interview-are well-known predictors of civic engagement and affect the likelihood of various labor market transitions. For instance, there is a well-established positive link between educational attainment and civic engagement (Musick and Wilson 2008), while we also know that job loss and labor force exits are more common among less-educated Americans-with the ongoing decline in labor force participation being sharpest amongst those with fewer qualifications (Krueger 2017). In addition, we take into account changes in living conditions between the two interviews, namely, changes in household income (increases and decreases of 25 percent or more), housing tenure (renting to owning and vice versa), marital status (entering and dissolving marital unions), and parental status (childbirth and children reaching primary-school age).[ENDNOTE 6] As some of these change variables could mediate the effects of labor market transitions on volunteer activities, we have run analyses with and without them. Because the results are virtually the same, we below present the analyses with the covariates measuring changes in living conditions. Section $\mathrm{C}$ of the online supplement includes the results from analyses without these covariates.

Table 1 presents descriptive statistics for volunteering and labor market status. Each cell corresponds to one labor market trajectory and contains: (i) the number of individuals following this trajectory; (ii) the relevant labor market transition rate; (iii) the initial volunteering rate among individuals following this trajectory. Descriptive statistics for the control variables are presented in Section A of the online supplement.

\section{$\ll<$ INSERT TABLE 1 HERE $\gg>$}

\subsection{Analytical strategy}

Exploiting the two-wave panel design of the CPS, we apply the principles of the change-score method (Allison 1990; Johnson 2005). Our analyses compare changes in volunteering among 
individuals with the same labor market status at T1 (i.e., at their first interview), of whom only some remain in that state at T2 (i.e., one year later). We estimate separate regression models for starting and stopping volunteering, because these events likely involve different social processes. This also restricts our comparisons to individuals with the same volunteering status at $\mathrm{T} 1$, further reducing potential biases due to unobserved heterogeneity.

Equation (1) summarizes the models that we estimate for starting volunteering, modeling for individual $i$ the $\log$ odds of volunteering $(V)$ at $\mathrm{T} 2$, given that one was not a volunteer at $\mathrm{T} 1$ (and thus "at risk" of starting). On the right-hand side of Equation (1), there is a vector of dummy variables for the labor market trajectories (LMT) that people follow between T1 and $\mathrm{T} 2$, and two vectors of control variables-one measuring states at $\mathrm{T} 1(X)$ and the other changes between $\mathrm{T} 1$ and $\mathrm{T} 2(Z)$. We include year fixed effects to control for changes over time that affect all individuals. For stopping volunteering, we estimate similar models, summarized in Equation (2). The left-hand side of this equation represents the log odds of not volunteering at $\mathrm{T} 2$, given that one was a volunteer at T1 (and thus "at risk" of stopping). The right-hand side is the same as in Equation (1).

$$
\begin{aligned}
& \log \left(\frac{P\left(V_{i, T 2}=1\right)}{P\left(V_{i, T 2}=0\right)} \mid V_{i, T 1}=0\right)=\alpha_{0}+\boldsymbol{\beta}_{L M T}[\boldsymbol{L M T}]_{i, T 1, T 2}+\boldsymbol{\beta}_{\boldsymbol{x}} \boldsymbol{X}_{\boldsymbol{i}, \boldsymbol{T 1}}+\boldsymbol{\beta}_{\mathbf{z}} \boldsymbol{Z}_{\boldsymbol{i}, \boldsymbol{T 1}, \boldsymbol{T 2}}+\gamma_{Y E A R} \\
& \log \left(\frac{P\left(V_{i, T 2}=0\right)}{P\left(V_{i, T 2}=1\right)} \mid V_{i, T 1}=1\right)=\alpha_{0}+\boldsymbol{\beta}_{L M T}[\boldsymbol{L M T}]_{i, T 1, T 2}+\boldsymbol{\beta}_{x} \boldsymbol{X}_{\boldsymbol{i}, T 1}+\boldsymbol{\beta}_{z} \boldsymbol{Z}_{i, T 1, T 2}+\gamma_{Y E A R}
\end{aligned}
$$

The fact that we construct our key variables from two interviews a year apart gives rise to some difficulties in terms of causal inference. First, because the volunteering question asks about activities in the past twelve months, the precise timing of starting or stopping volunteering is uncertain. Second, we neither know when exactly changes in labor market status occur. As a result, changes in volunteer status may precede changes in labor market status among some respondents. Finally, we may fail to capture all changes in labor market status that occur between T1 and T2. For example, some people who are employed at both T1 and T2 may experience a spell of unemployment in between. Therefore, we may overestimate the degree of labor market stability among the "stable employed". In Section 4.4 we discuss robustness checks performed in response to these issues.

\section{Findings}


We start this section by looking at the general influence of labor market trajectories on changes in volunteering. Next, we consider several explanatory mechanisms. We report our results in graphs depicting predicted probabilities of starting and stopping volunteering. The underlying regression tables are available in Section $\mathrm{C}$ of the online supplement.

\subsection{Labor market experiences and civic participation}

Figure 2 plots average predicted probabilities of starting and stopping volunteering by labor market trajectory, generated from logistic regressions as discussed in Section 3.3. Each subgraph concerns labor market trajectories that start from the same origin at $\mathrm{T} 1$ but reach different destinations at $\mathrm{T} 2$.

\section{《< INSERT FIGURE 2 HERE $\gg>$}

With respect to the control variables measured at $\mathrm{T} 1$, most results are consistent with earlier research. Furthermore, changes in living conditions also help to explain changes in volunteering. Major drops in household income, for example, discourage starting and stimulate quitting, and while childbirth hampers starting and increases quitting, children's school entry is linked to a higher take-up of volunteer work. See Section C of the online supplement for details.

Turning to the influence of labor market trajectories, Figure 2 contains no evidence that unemployment suppresses civic engagement, contrary to what much previous research suggests. If anything, we find the opposite. Compared to individuals who are employed in both periods, those who move from employment to unemployment are almost two percentage points more likely to start volunteer work - a 12 percent increase in the starting probability - and no more likely to quit (see the top graphs in Figure 2). Moreover, among people unemployed at T1, those who remain unemployed are four percentage points more likely to start and eight percentage points less likely to stop volunteering than those who find a job: differences in the starting and quitting probability of, respectively, 21 and 27 percent (the middle graphs in Figure 2). These differences equal or exceed the influence of sex, race, parental status, or several years of education. 
Importantly, Figure 2 indicates that moving into and out of the labor force is more consequential for volunteering activities than moving between employment and unemployment is. Leaving the labor force - either from employment or unemployment - is related to an elevated risk of discontinuing volunteer activities among existing volunteers (the first two graphs of Panel B). This differential is most pronounced among individuals who are initially unemployed, with a stopping probability of 39 percent for those who subsequently leave the labor force versus 29 percent for those who remain unemployed. Moving from unemployment to NILF status is also linked to a lower probability to start volunteering.

Conversely, labor force entry increases the probability of getting involved in voluntary work. This rise is largest when one moves into unemployment (the bottom-left graph of Figure 2). More specifically, the probability to start volunteering is 13 percent for people who reside outside the labor force in both periods, but more than 22 percent for labor force outsiders who have begun a job search at T2 - thus becoming unemployed. This latter starting probability is higher than for any other labor market trajectory.

In sum, Figure 2 suggests that moving from employment to unemployment has a modest positive net impact on volunteering, while moving from unemployment to employment tends to undermine volunteer work. Moreover, movements into and out of the labor force have bigger impacts than most movements within the labor force (i.e., between employment and unemployment). Dropping out of the labor force suppresses volunteering, mainly by making existing volunteers abandon their activities, while entering the labor force promotes volunteering, primarily by encouraging non-volunteers to become involved.

Our novel findings about labor force entries and exits support our general predictions that shifts toward greater labor market integration boost civic participation, with the opposite being true for shifts in the other direction; see hypotheses 1a and 2a in Section 2.2.3. Figure 2 additionally demonstrates that the specific combinations of labor market origins and destinations are key in explaining changes in volunteering. For transitions within the labor force, a stronger sense of social membership and more work-based ties among the employed appear outweighed by increased instrumental incentives and time available for volunteering among the unemployed. Yet, when people stop searching for work and exit the labor force entirely, the forces that inhibit civic engagement begin to dominate. These patterns - in line with hypotheses $1 b$ and $2 b$ in 
Section 2.2.3 - could reflect that labor force exits imply a weakening of individuals' sense of purpose as well as their instrumental incentives for voluntary work.

\subsection{The role of work desires and motivation}

Although labor force entry and exit seem critical transitions for civic participation, labor force outsiders constitute a heterogeneous group, among other things in terms of their labor market attachment. Figure 3 therefore presents average predicted probabilities of starting and stopping volunteering based on models that separate labor force outsiders who express a desire to find paid work from those who do not. We make this distinction using the survey question: "Do you currently want a job, either full- or part-time?'[ENDNOTE 7] While both groups may be similar in their time availability and lack of work-based social connections, they differ in their attachment to the labor market. These analyses can thus elucidate the role of motivational factors for one's decision to volunteer. After all, despite not being counted as unemployed according to the BLS definitions, labor force outsiders with a desire to find work face stronger career-related instrumental incentives for civic participation and may possess a stronger sense of purpose.

\section{$\ll$ INSERT FIGURE 3 HERE $\gg>$}

Panel A of Figure 3 illustrates that the positive impact of labor force entry on starting volunteering hinges on whether one already wanted a job while still outside the labor force. If so, labor force entry has no additional effect (the bottom-left graph in Panel A). Yet, if one initially did not express a desire to find work, labor force entry strongly boosts the starting probability, from 13 to 19 or 24 percent depending on the destination (the bottom-right graph in Panel A). In fact, merely acquiring a desire to find work while remaining outside the labor force provides a similar boost.

In Panel B we observe a comparable pattern for stopping volunteering, with the civic impact of labor force exits being contingent on whether one maintains a desire to find work. As the top graphs in Panel B illustrate, only individuals who no longer want a job are more likely to give up their volunteer work when dropping out of the labor force. Furthermore, when labor force outsiders who initially wanted to find a job lose this desire, their probability to stop volunteering 
goes up (the bottom-left graph), while acquiring such a desire is associated with a lower stopping probability (the bottom-right graph).

Overall, it is only when people lose or gain ambitions to find work that labor force entry and exit evoke substantial shifts in volunteering. This finding supports hypothesis $2 \mathrm{~b}$ in Section 2.2.3 and holds while adjusting for, among other things, changes in health, marital and parental status. Civic participation, in other words, seems deeply rooted in people's motivation to participate in paid work. This may reflect the role of career-related instrumental incentives or that a loss of work ambitions can weaken people's sense of purpose and elicit feelings of superfluity, denting their motivation to take part in public life. Regardless of the underlying mechanisms, these findings are troubling given the growing number of prime working-age people who remain outside the labor force without looking for work.

It is, however, important to stress that a loss of work ambitions does not always represent an active choice. Indeed, it may also reflect poor labor market conditions. In this context, the Council of Economic Advisers (2016) concludes that a declining demand for low-skilled labor is critical for explaining the drop in prime-age male labor force participation in the United States. These worsened job opportunities make jobless individuals more likely to give up on finding new employment.

\subsection{The role of work hours as time constraint}

We now address the influence of time availability as a resource constraint. For this purpose, Figure 4 shows how the influence of various labor market trajectories on volunteering decisions depends on changes in work hours between $\mathrm{T} 1$ and $\mathrm{T} 2$. Once more, we present average predicted probabilities of starting and stopping volunteering, but this time based on models that include interactions between labor market trajectories and changes in work hours.[ENDNOTE 8] For the stable employment group, we only present predicted probabilities for changes in weekly work hours from -25 to +25 , as only one percent of this group experience larger changes.

\section{$\longleftrightarrow$ INSERT FIGURE 4 HERE $\gg>$}

Some patterns in Figure 4 support the idea that greater time availability stimulates civic engagement. In line with hypothesis $1 \mathrm{~b}$ in Section 2.2.3, starting jobs with higher time demands 
makes individuals less likely to start volunteering (see the trajectories $\mathrm{U} \rightarrow \mathrm{E}$ and $\mathrm{N} \rightarrow \mathrm{E}$ in Panel A) and more likely to give up existing volunteer activities (see the same trajectories in Panel B). For example, when an unemployed non-volunteer finds a 15 -hour job, their probability to start volunteering equals 17 percent; yet when their new job demands 45 hours a week, their starting probability is only 11 percent. This is what we would expect if working time and volunteering time compete with one another.

However, Figure 4 also displays patterns that contradict the notion that work hours constrain civic participation. This is especially evident for individuals who exit the labor force after losing their job (see the $\mathrm{E} \rightarrow \mathrm{N}$ trajectory in Panels A and B). Our model predicts that 44 percent of all volunteers who exit the labor force after losing a 45-hour job stop volunteering, versus 33 percent of those who used to work 15 hours a week. The corresponding starting percentages are 11 and 16 percent, respectively. These patterns run counter to what the time availability mechanism predicts. After all, compared to people losing less time-consuming jobs, those who lose more time-consuming jobs gain more time that could then be spent on civic activities. Yet, they are less likely to start volunteering and more likely to quit.

Our findings thus highlight that time availability alone cannot explain the links between labor market experiences and changes in civic participation. Time constraints matter when people start jobs, but for transitions out of employment other forces seem to trump the effects of additional free time. Career-related instrumental incentives can neither explain why people who leave more time-demanding jobs are more likely to pull out of civic life than those who leave less-demanding jobs. Instead, these patterns point to the socio-psychological scars of job loss, which may comprise an erosion of people's motivation for civic engagement and a reduction in their civic opportunities. Such damages are likely more significant when one loses a more timeconsuming job, as job loss would then represent a more disruptive life event.

Finally, for the continuously employed, the effects of changing work hours are small but complex. For example, Panel B shows that among this group both increases and decreases in work hours make existing volunteers slightly more likely to quit, while Panel A suggests that increases in work hours are also linked to a higher starting probability. Although the associated differences in the probabilities to start and stop volunteering are small, these conflicting findings are difficult to explain with time availability alone and may reflect unobserved changes such as promotions and switching between employers. 


\subsection{Robustness checks, additional analyses, and remaining challenges}

We have conducted a number of robustness checks and additional analyses, the results of which are presented in Section D of the online supplement.

First, we have replicated all analyses while only including prime working-age (25-54) respondents, to assess whether our findings still hold when excluding most transitions out of schooling and into retirement. This turns out to be the case. Second, we have repeated all analyses for men and women separately. Women are, in general, more likely to start and less likely to stop volunteering, but contrary to some previous studies (e.g., Taniguchi 2006), we find that most labor market experiences have very similar impacts across both sexes. Third, we have examined whether labor market experiences have different effects for people who have attended college versus those with only high school or less, recognizing that recent declines in labor force participation have been most pronounced among the latter (Krueger 2017). However, the links between labor market transitions and civic participation appear largely the same across both groups. Fourth, we have separately considered volunteering for organizations in the following areas: children, religion, community, culture, environment, health, politics, and work. Barring a few exceptions, we find consistent patterns across all organization types. Fifth, given the importance of religion in American civic life and our inability to measure this factor directly, we have rerun our analyses restricted to respondents who did not volunteer for religious organizations at $\mathrm{T} 1$ or $\mathrm{T} 2$. These analyses yield results similar to those presented above, indicating that religious involvement is unlikely to be a major confounder. Sixth, we have considered changes in the number of hours volunteered as alternative outcome variable. Again, we manage to replicate our main findings.

Besides these robustness checks, we have examined the roles that individuals fulfil outside the labor force, because the degree to which a weaker labor market integration undermines civic engagement may depend on whether people have alternative sources of identity and purpose outside the labor market. We find that being outside the labor force for schooling/training is in fact conducive to volunteering. To some degree this also applies to labor force outsiders who are looking after their family or household, although it seems that time spent on these activities can also come at the expense of volunteer work. Dropping out of the labor force into a situation of disability or illness is most strongly associated with a retreat from civic life. That said, when 
we exclude everyone who is classified as retired or disabled at $\mathrm{T} 1$ and/or T2, we still find substantial civic effects of labor force entries and exits.

To test the role of work-based social connections, we have looked at different pathways into volunteering, differentiating people who get involved on their own initiative from those who join after being asked. If work-related connections are key to civic engagement, we would, for instance, expect that transitions into employment primarily boost volunteering via interpersonal recruitment. We find, however, no support for such predictions. Moreover, among people who start volunteering after being asked, only eight percent report having been recruited by their colleagues. The role of work-based connections as recruitment channel thus seems limited.

Recognizing that labor market experiences are not randomly distributed across the population, we have also investigated to what extent our findings may be driven by non-random selection of individuals into different labor market trajectories. For this purpose, we have applied the diagnostic routine proposed by Morgan and Todd (2008), conducting weighted regressions that correct for individuals' likelihood to experience particular labor market trajectories. The resulting estimates are similar to the results presented above. Although we acknowledge that observational studies like ours are inevitably susceptible to unobserved heterogeneity, these results offer further assurance about the robustness of our findings.

Finally, we return to the issues concerning our key variables discussed in Section 3.3. First, the fact that the CPS asks respondents about any volunteering activities over the past twelve months, together with the fact that volunteering often concerns infrequent activities, implies that people whom we classify as volunteers may not actually be civically active at the time of their interview. To examine how this may affect our findings, we have replicated our analyses while distinguishing between "high-frequency" and "low-frequency" volunteers, depending on whether people engaged in volunteering activities during at least 24 weeks of the year. While high-frequency volunteers are more likely to be civically active near the time of their interview, our findings turn out very similar whether we look at high-frequency or low-frequency volunteering. This suggests that any biases due to our imprecise measurement of the timing of volunteering activities are minimal. 
Second, because our labor market trajectory variable is constructed from respondents' labor market states at two interviews a year apart, it may fail to capture all labor market experiences that occur in the meantime. To explore the frequency and duration of intermediate labor market states, we have used the March surveys of the CPS — which contain retrospectively reported, complete labor market histories over the preceding calendar year-combined with the January and December surveys. We find that such intermediate states are most common among respondents who start off from or end up in unemployment, but rare among all other respondents, occurring among roughly 10 percent of the latter. Moreover, any intermediate labor market spells tend to be brief, lasting on average only a few weeks, except for people who are unemployed at the beginning and end of the calendar year. As such, our labor market trajectory variable will usually capture the main labor market states that respondents experience during the year. The prime exception concerns respondents classified as "stable unemployed", who often experience greater fluidity than this label suggests.

Following from the previous two points, there remains some uncertainty regarding the time ordering of labor market transitions and changes in volunteering status-a limitation shared with previous panel studies in this area (e.g., Lancee and Radl 2014). It is, therefore, possible that the latter precede or even drive the former in some cases. This is, however, not the most plausible scenario for many of our findings. For example, it seems unlikely that the act of stopping volunteering leads the unemployed to new jobs or makes people leave the labor force. More generally, longitudinal studies on the labor market payoffs of volunteering conclude that changes in volunteering influence labor market outcomes only under certain circumstances (Qvist and Munk 2018; Ruiter and De Graaf 2009). That said, reverse causality might play a role in explaining our findings on labor force entry: it is quite possible that the act of starting volunteering motivates labor force outsiders to enter the labor force.

\section{Conclusion}

In this study we have addressed how labor market experiences give rise to shifts in civic engagement, focusing on volunteer activities. We have first presented a theoretical framework of how transitions to greater or weaker labor market integration may alter people's motivations, resources, and opportunities for volunteering. Our empirical analyses have subsequently revealed novel findings that advance our understanding of the links between the labor market 
and civic life, thereby informing debates on the societal consequences of ongoing labor market trends.

Contrary to what much previous work suggests, we do not find that being or becoming unemployed (i.e., jobless but actively searching for work) undermines civic engagement. Becoming unemployed is associated with a somewhat higher probability to start volunteering among non-volunteers, and existing volunteers who become unemployed are no more likely to stop volunteering than those continuously employed. So, to the extent that unemployment harms people socially, psychologically, or financially, this damage appears insufficient to weaken their civic involvement.

These findings are obtained from analyses that relate changes in labor market status to changes in civic participation and use a more fine-grained definition of unemployment than in most previous work. Both factors help to explain the discrepancy between our findings and those of previous studies. Another factor behind this incongruence might be that many previous studies consider earlier time periods with different labor market contexts. The relationships between labor market experiences and civic engagement might have changed in the meantime and our findings may be unique to the current context. That said, within our study window we find little evidence of such changes over time.

Whereas earlier research pays little attention to the civic impacts of labor force entry and exit, we find that labor force entrants (i.e., labor force outsiders who enter employment or start searching for work) are much more likely to take up volunteer activities, while people who leave the labor force are more likely to withdraw from civic life. People's attachment to the labor market seems key to explaining these patterns. Labor force exits only hurt volunteering when people also lose their desire to find paid work. Similarly, regaining this desire boosts people's involvement in volunteer activities, even when they do not actively search for work and thus remain outside the labor force. It additionally matters whether labor force outsiders fulfil other roles that give them purpose and serve as a source of social integration. Hence, more than the experience of certain labor market transitions per se, it seems critical whether they evoke a shift in people's sense of purpose and their drive to participate in public life.

Our findings underscore that participation in the labor market and civic life are closely linked. As such, a weakening connection to the labor force can translate into a more general retreat 
from public life. This is an alarming observation in view of declining labor force participation in the United States, particularly among prime working-age men (Krueger 2017). It suggests that the rising number of people outside the labor force may also lose touch with other domains of social life. This threat is only more pertinent given that many labor force outsiders are having a hard time re-entering employment (Kroft et al. 2016) and thus have become increasingly detached from the workforce (Council of Economic Advisers 2016; Krueger 2017). Furthermore, while a plethora of explanations have been proposed for the declining trend in labor force participation - including increased take-up of disability benefits, higher minimum wages, limited childcare availability, increases in the value of leisure time due to new entertainment options, declining geographic mobility, and risen opioid consumption - these declines are primarily driven by reductions in labor demand due to increased exposure to trade and technological innovations (Abraham and Kearney 2018). Since these forces will remain relevant in the coming years, the decline in labor force participation is likely to continue. In light of our findings, the resulting rise in the number of people disconnected from the labor force has the potential to significantly undermine civic democracy and social cohesion.

From a theoretical viewpoint, our results reveal a complex interplay of various mechanisms in shaping the effects of labor market experiences on civic participation. For instance, while we demonstrate that time resources can facilitate civic participation, in line with dominant theoretical models (e.g., Verba et al. 1995), having more free time is on its own insufficient for pulling people into civic life. Our results rather suggest that time resources only become relevant once there is a motivation to participate in public life. With respect to this motivation, our findings highlight the potential relevance of instrumental incentives, even though these are often dismissed in favor of altruistic and solidary values or "social" and "purposive" incentives in the civic participation literature (e.g., Hwang, Grabb, and Curtis 2005). Instrumental motives seem especially relevant for trajectories involving unemployment, consistent with the idea that civic participation can provide numerous benefits to job seekers. Still, some of our findings point to a deeper link between labor market integration, people's sense of belonging and purpose, and their motivation to take part in civic life.

In sum, mechanisms related to time resources, instrumental motives, and sense of social membership likely co-produce the observed associations between labor market experiences and changes in volunteering. Which of these mechanisms are dominant depends on the precise labor market trajectory that people follow. 
In extending this line of inquiry, future research needs to further dissect variation in labor market integration among the employed, especially given trends toward more instable and precarious employment (Hollister and Smith 2014; Kalleberg 2011). After all, people in stable jobs with attractive contracts are more solidly integrated into the labor market than those who hop from one precarious job to another (Wilensky 1961; Rotolo and Wilson 2003; Gundert and Hohendanner 2014). Similarly, factors such as self-employment and occupational prestige may also have implications for one's sense of community attachment and one's incentives for civic engagement (Musick and Wilson 2008). In addition, there are people who work less than they would want to, who have to take on multiple jobs to make ends meet, and whose skill set exceeds their job requirements. Our analytical framework can be readily applied to explore such variation and its impact on civic engagement.

It would, furthermore, be valuable to exploit data with a longer time frame, more time points per individual, and thus more complete labor market and volunteering histories. This would allow an assessment of whether the impacts of certain labor market experiences are transient and reversible or permanent (cf. Brand and Burgard 2008; Laurence 2015). Such analyses are essential concerning the longer-run consequences of ongoing labor market trends. Moreover, they could reveal how past experiences influence the impact of particular labor market transitions (cf. Clark, Georgellis, and Sanfey 2001) and help to more firmly establish the time ordering of changes in labor market and volunteer status.

Finally, while this study has taken an individual-level approach, further insights may be gained by adopting a household-level perspective. In particular, it would be interesting to explore potential intra-household spillovers regarding the civic effects of labor market experiences. Such spillovers could, for instance, entail that increased labor market detachment of the household head also leads to civic withdrawal among other household members. This would mean that diminished labor market integration not only puts individuals but whole families at risk of social isolation.

\section{References}


Abraham, Katharine G., Sara Helms, and Stanley Presser. 2009. "How Social Processes Distort Measurement: The Impact of Survey Nonresponse on Estimates of Volunteer Work in the United States." American Journal of Sociology 114:1129-65.

Abraham, Katharine G., and Melissa S. Kearney. 2018. "Explaining the Decline in the U.S. Employment-to-Population Ratio: A Review of the Evidence." NBER Working Paper 24333.

Aguiar, Mark, Mark Bils, Kerwin K. Charles, and Erik Hurst. 2018. "Leisure Luxuries and the Labor Supply of Young Men.” Working paper. Weblink: https://scholar.princeton.edu/ maguiar/publications/leisure-luxuries-and-labor-supply-young-men (most recently visited May 17th, 2018).

Allison, Paul D. 1990. "Change Scores as Dependent Variables in Regression Analysis." Sociological Methodology 20:93-114.

Borgonovi, Francesca. 2008. "Doing Well by Doing Good. The Relationship between Formal Volunteering and Self-Reported Health and Happiness." Social Science \& Medicine 66:2321-34.

Brand, Jennie E., and Sarah A. Burgard. 2008. "Effects of Job Displacement on Social Participation: Findings over the Life Course of a Cohort of Joiners." Social Forces 87:211-42.

Brand, Jennie E. 2015. "The Far-Reaching Impact of Job Loss and Unemployment.” Annual Review of Sociology 41:359-75.

Chen, Victor Tan. 2015. Cut Loose: Jobless and Hopeless in an Unfair Economy. Oakland, CA: University of California Press.

Clark, Andrew E., Yannis Georgellis, and Peter Sanfey. 2001. "Scarring: The Psychological Impact of Past Unemployment.” Economica 68:221-41.

Clark, Tom, and Anthony F. Heath. 2014. Hard Times: The Divisive Toll of the Economic Slump. New Haven, CT: Yale University Press.

Council of Economic Advisers. 2016. The Long-Term Decline in Prime-Age Male Labor Force Participation. Weblink: https://obamawhitehouse.archives.gov/sites/default/files/page/ files/20160620_cea_primeage_male_lfp.pdf (most recently visited May 17 $\left.{ }^{\text {th }}, 2018\right)$.

Erlinghagen, Marcel. 2000. "Arbeitslosigkeit und ehrenamtliche Tätigkeit im Zeitverlauf." Kölner Zeitschrift für Soziologie und Sozialpsychologie 52:291-310.

Freeman, Richard B. 1997. "Working for Nothing: The Supply of Volunteer Labor.” Journal of Labor Economics 15:S140-S167. 
Gundert, Stefanie, and Christian Hohendanner. 2014. "Do Fixed-Term and Temporary Agency Workers Feel Socially Excluded? Labour Market Integration and Social Well-Being in Germany." Acta Sociologica 57:135-52.

Hollister, Matissa N., and Kristin E. Smith. 2014. "Unmasking the Conflicting Trends in Job Tenure by Gender in the United States, 1983-2008." American Sociological Review 79:159-81.

Hustinx, Lesley, Ram A. Cnaan, and Femida Handy. 2010. "Navigating Theories of Volunteering: A Hybrid Map for a Complex Phenomenon." Journal for the Theory of Social Behavior 40:410-34.

Hwang, Monica, Edward Grabb, and James Curtis. 2005. "Why Get Involved? Reasons for Voluntary-Association Activity Among Americans and Canadians." Nonprofit and Voluntary Sector Quarterly 34:387-403.

Jahoda, Marie. 1982. Employment and Unemployment: A Social-Psychological Analysis. Cambridge: Cambridge University Press.

Jahoda, Marie, Paul F. Lazarsfeld, and Hans Zeisel. 2002[1933]. Marienthal. New Brunswick, NJ: Transaction Publishers.

Johnson, David. 2005. "Two-Wave Panel Analysis: Comparing Statistical Methods for Studying the Effects of Transitions." Journal of Marriage and Family 67: 1061-75.

Kalleberg, Arne L. 2011. Good Jobs, Bad Jobs: The Rise of Polarized and Precarious Employment Systems in the United States, 1970s-2000s. New York, NY: Russell Sage Foundation.

Kroft, Kory, Fabian Lange, Matthew J. Notowidigdo, and Lawrence F. Katz. 2016. "LongTerm Unemployment and the Great Recession: The Role of Composition, Duration Dependence, and Non-Participation.” Journal of Labor Economics 34:S7-S54.

Krueger, Alan B. 2017. "Where Have All the Workers Gone? An Inquiry into the Decline of the U.S. Labor Force Participation Rate.” Brookings Papers on Economic Activity Fall 2017:1-87.

Krueger, Alan B., and Andreas Mueller. 2010. "Job Search and Unemployment Insurance: New Evidence from Time Use Data.” Journal of Public Economics 94:298-307.

Lamont, Michèle. 2000. The Dignity of Working Men: Morality and the Boundaries of Race, Class, and Immigration. New York, NY: Russell Sage Foundation.

Lancee, Bram, and Jonas Radl. 2014. "Volunteering over the Life Course." Social Forces 93:833-62. 
Laurence, James. 2015. “(Dis)placing Trust: The Long-Term Effects of Job Displacement on Generalised Trust over the Adult Lifecourse.” Social Science Research 50:46-59.

Lim, Chaeyoon, and James Laurence. 2015. "Doing Good when Times are Bad: Volunteering Behaviour in Economic Hard Times.” British Journal of Sociology 66:319-44.

Lim, Chaeyoon, and Thomas Sander. 2013. "Does Misery Love Company? Civic Engagement in Economic Hard Times.” Social Science Research 42:14-30.

Morgan, Stephen L., and Jennifer J. Todd. 2008. "A Diagnostic Routine for the Detection of Consequential Heterogeneity of Causal Effects." Sociological Methodology 38:231-81.

Musick, Marc A., and John Wilson. 2008. Volunteers: A Social Profile. Bloomington, IN: Indiana University Press.

Piatak, Jaclyn S. 2016. "Time is on my Side: A Framework to Examine when Unemployed Individuals Volunteer.” Nonprofit and Voluntary Sector Quarterly 45:1169-90.

Prouteau, Lionel, and François-Charles Wolff. 2006. "Does Volunteer Work Pay Off in the Labor Market?” Journal of Socio-Economics 35:992-1013.

Putnam, Robert D. 2000. Bowling Alone: The Collapse and Revival of American Community. New York, NY: Simon and Schuster.

Qvist, Hans-Peter Y., and Martin D. Munk. 2018. "The Individual Economic Returns to Volunteering in Work Life.” European Sociological Review 34:198-210.

Rivera Drew, Julia A., Sarah Flood, John R. Warren. 2014. "Making Full Use of the Longitudinal Design of the Current Population Survey: Methods for Linking Records across 16 Months.” Journal of Economic and Social Measurement 39:121-144.

Rotolo, Thomas. 2000. “A Time to Join, a Time to Quit: The Influence of Life Cycle Transitions on Voluntary Association Membership." Social Forces 78:1133-61.

Rotolo, Thomas, and John Wilson. 2003. "Work Histories and Voluntary Association Memberships." Sociological Forum 18:603-19.

Rotolo, Thomas, John Wilson, and Mary E. Hughes. 2010. "Homeownership and Volunteering: An Alternative Approach to Studying Social Inequality and Civic Engagement." Sociological Forum 25:570-87.

Ruiter, Stijn, and Nan Dirk de Graaf. 2009. "Socio-Economic Payoffs of Voluntary Association Involvement: A Dutch Life Course Study.” European Sociological Review 25:425-42.

Spera, Christopher, Robin Ghertner, Anthony Nerino, and Adrienne DiTommaso. 2015. "Out of Work? Volunteers Have Higher Odds of Getting Back to Work." Nonprofit and Voluntary Sector Quarterly 44:886-907. 
Strauß, Susanne. 2008. "Unemployment and Other Forms of Social Exclusion: Job Loss and its Consequences on Civic Engagement in Germany and Great Britain.” Eberhard Karls Universität Tübingen: ESOC Working Paper 4/2008.

Taniguchi, Hiromi. 2006. “Men's and Women's Volunteering: Gender Differences in the Effects of Employment and Family Characteristics." Nonprofit and Voluntary Sector Quarterly 35:83-101.

Verba, Sidney, Kay L. Schlozman, and Henry E. Brady. 1995. Voice and Equality: Civic Voluntarism in American Politics. Cambridge, MA: Harvard University Press.

Wilensky, Harold L. 1961. "Orderly Careers and Social Participation: The Impact of Work History on Social Integration in the Middle Mass." American Sociological Review 26:521-39.

Wilson, John. 2000. "Volunteering.” Annual Review of Sociology 26:215-40.

\section{Endnotes}

1. The labor force consists of everyone who is employed or unemployed (i.e., jobless but actively looking for work). Accordingly, labor force entry can occur via employmentwhen a labor force outsider finds a job — or via unemployment — when a labor force outsider begins an active job search.

2. One potential source of attrition bias relates to the CPS not following respondents when they move, which accounts for nearly half of all unsuccessful matches. Some moves may be induced by labor market transitions, while moving may also be negatively associated with civic participation (Rotolo, Wilson, and Hughes 2010). However, mobility statistics over the 2002-2015 period indicate that only 10 percent of all moves are related to new jobs, job search, or job loss.

3. We have also carried out multiple imputations for the cases with missing income data (13 percent of all respondents; no other variables have missing values). We generated twenty imputed datasets based on OLS regressions of log household income on all other variables in our analyses as well as state identifiers and household size. Analyses with the imputed data yield results almost identical to those reported in the paper. 
4. To check whether our findings concerning volunteer work are generalizable to other forms of civic engagement, we have replicated our analyses with "attending public meetings" and "working together with neighbors" as outcome variables. Most findings remain the same when looking at these alternative outcomes. See Section D of the online supplement for details.

5. Another potential confounding factor is respondents' health status, which we are able to measure since 2009, when the CPS began to ask respondents whether they experience problems with hearing, eyesight, concentration/memory/decision-making, dressing/bathing, walking/climbing stairs, and running errands. We use this information to construct an additive health index. Incorporating initial health status and changes in health in our analyses, we find that both factors help to predict shifts in volunteering, but our core results are not affected by their inclusion. See Sections C and D of the online supplement.

6. In supplementary analyses (not presented), we have also controlled for other changes in parental status, to capture for example the influence of becoming an "empty-nester". Our core results remain unchanged when we include these additional controls.

7. Retired and disabled individuals are not asked this question. At the same time, both groups have low labor force entry rates of, respectively, three and five percent vis-à-vis nearly 30 percent for all other labor force outsiders. Therefore, we group them together with labor force outsiders expressing no desire to find work. Nonetheless, we obtain similar results when we exclude them altogether. Overall, six percent of all labor force outsiders express a desire to find work; without the retired and disabled, this is 14 percent.

8. Due to missing values for the work hours variable, the analyses underlying Figure 4 cover 317,917 individuals (a reduction of nine percent compared to our main sample). For people employed at both $\mathrm{T} 1$ and $\mathrm{T} 2$, we allow for differential effects of increases and decreases in work hours. 
Table 1 Descriptive statistics across our sample of analysis $(\mathrm{N}=348,901)$, separately for each labor market trajectory

\begin{tabular}{|c|c|c|c|c|c|c|c|}
\hline & & \multicolumn{6}{|c|}{ Labor market status at time T2 } \\
\hline & & \multicolumn{2}{|c|}{ Employed [E] } & \multicolumn{2}{|c|}{ Unemployed [U] } & \multicolumn{2}{|c|}{ NILF [N] } \\
\hline Ё & Employed [E] & $N=198,298$ & $\begin{array}{c}P(E \mid E)=91.6 \% \\
V(0)=35.9 \%\end{array}$ & $N=5,174$ & $\begin{array}{c}P(U \mid E)=2.4 \% \\
V(0)=27.5 \%\end{array}$ & $N=13,031$ & $\begin{array}{l}P(N \mid E)=6.0 \% \\
V(0)=33.3 \%\end{array}$ \\
\hline 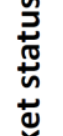 & Unemployed [U] & $N=5,837$ & $\begin{array}{c}P(E \mid U)=46.6 \% \\
V(0)=31.7 \%\end{array}$ & $N=3,241$ & $\begin{array}{c}P(U \mid U)=25.9 \% \\
V(0)=24.0 \%\end{array}$ & $N=3,449$ & $\begin{array}{c}P(N \mid U)=27.5 \% \\
V(0)=27.3 \%\end{array}$ \\
\hline 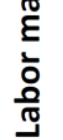 & NILF [N] & $N=11,330$ & $\begin{array}{l}P(E \mid N)=9.5 \% \\
V(0)=33.7 \%\end{array}$ & $N=3,041$ & $\begin{array}{c}P(U \mid N)=2.5 \% \\
V(0)=27.3 \%\end{array}$ & $N=105,500$ & $\begin{array}{c}P(N \mid N)=88.0 \% \\
V(0)=26.8 \%\end{array}$ \\
\hline
\end{tabular}

Note: This is a three-by-three matrix of the nine labor market trajectories that people can follow from time T1 to time T2 between the main labor market states. Rows denote labor market status at time T1, columns denote labor market status at time T2. For each labor market trajectory, we report the total number of individuals following this particular trajectory $(N)$, the accompanying transition rate from the initial labor market state $(P(. . \mid)$.$) , and the initial volunteering rate among individuals following this trajectory \left(V_{0}\right)$. 
Figure 1 Relationships between the drivers of civic engagement and labor market integration
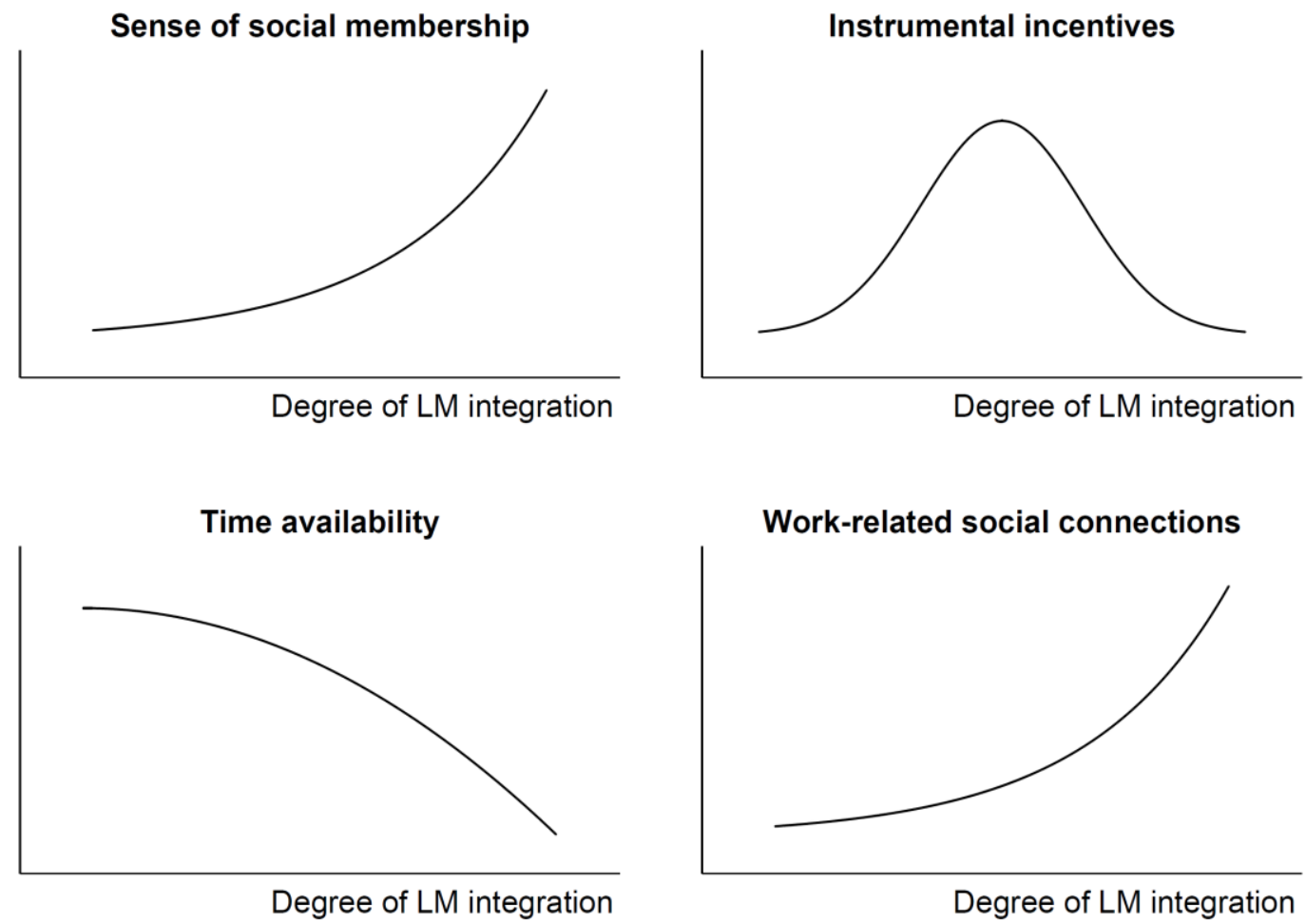

Note: These graphs serve as visual approximations of our expectations; the precise positioning, curvature, and skewness of the graphs do not necessarily exactly reflect our expectations. "LM" stands for labor market. 
Figure 2 Predicted probabilities of starting and stopping volunteering by labor market trajectory

A. Probability of starting volunteering

Origin: Employed

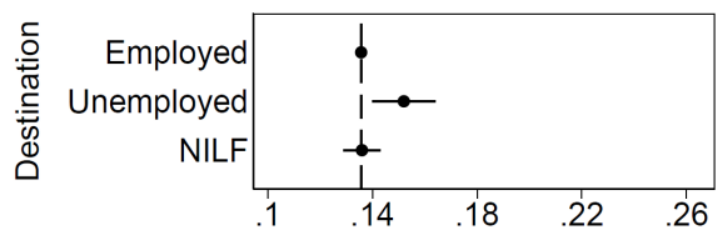

Origin: Unemployed

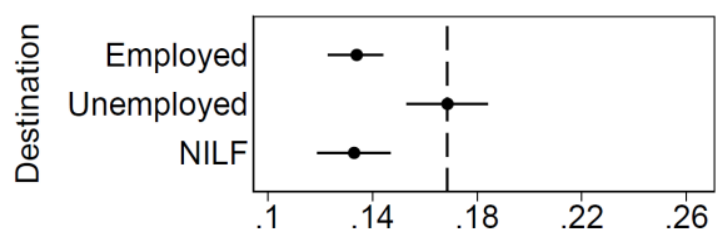

Origin: NILF

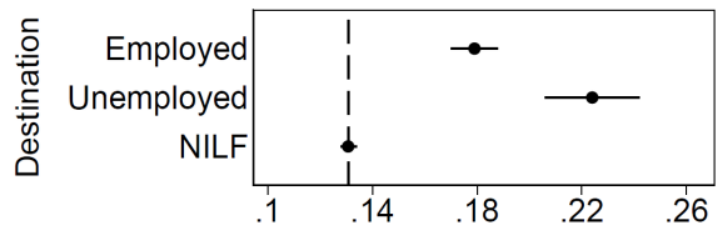

B. Probability of stopping volunteering

Origin: Employed

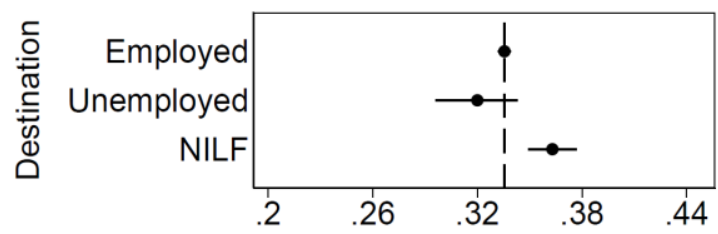

Origin: Unemployed

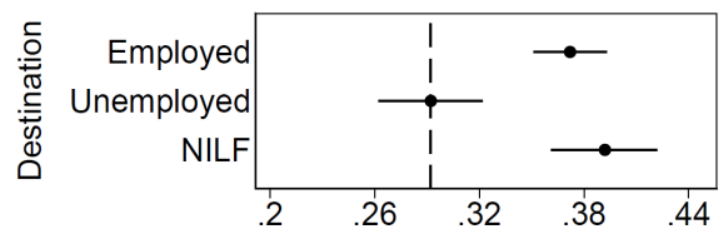

Origin: NILF

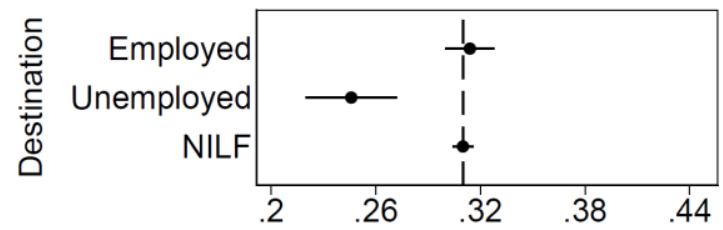

Note: The underlying models include all control variables mentioned in Section 3.2. Holding these constant at their actual value for each individual, we plot the average predicted probabilities across the sample of analysis. The error bars denote 95 percent confidence intervals. The dashed vertical lines correspond to the predictions for individuals experiencing no labor market transition. The starting analyses comprise 235,529 individuals; the stopping analyses comprise 113,372 individuals. 
Figure 3 Predicted probabilities of starting and stopping volunteering by labor market trajectory, distinguishing labor force outsiders by the desire to find paid work

A. Probability of starting volunteering
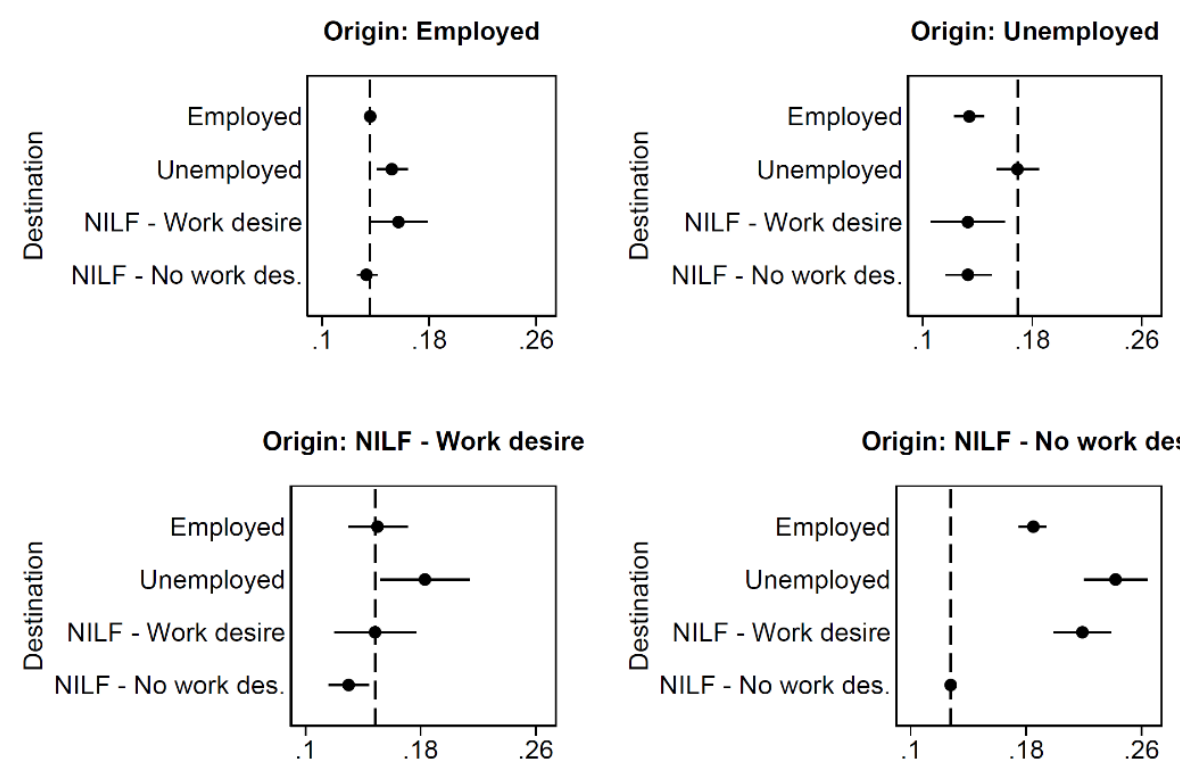

B. Probability of stopping volunteering
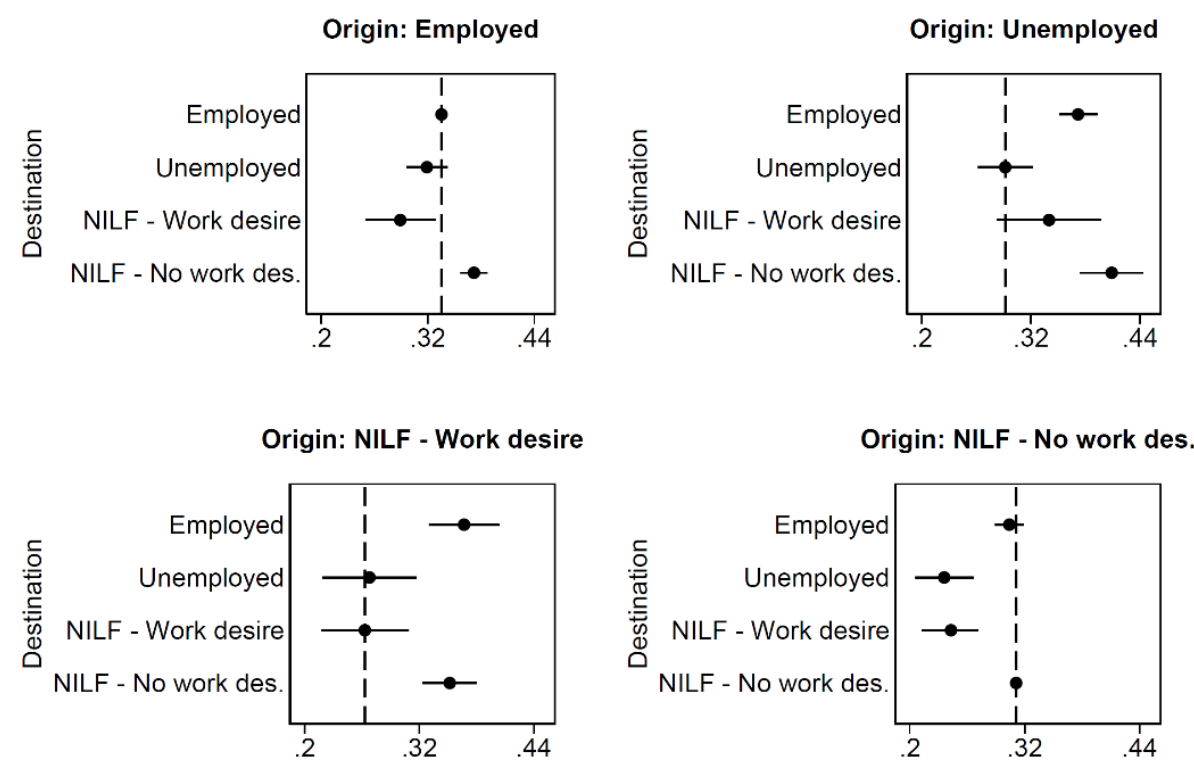

Note: The underlying models include all control variables mentioned in Section 3.2. Holding these constant at their actual value for each individual, we plot the average predicted probabilities across the sample of analysis. The error bars denote 95 percent confidence intervals. The dashed vertical lines correspond to the predictions for people experiencing no labor market transition. The starting analyses comprise 235,529 individuals; the stopping analyses comprise 113,372 individuals. 
Figure 4 Predicted probabilities of starting and stopping volunteering by labor market trajectory, exploring the influence of changes in work hours

A. Probability of starting volunteering

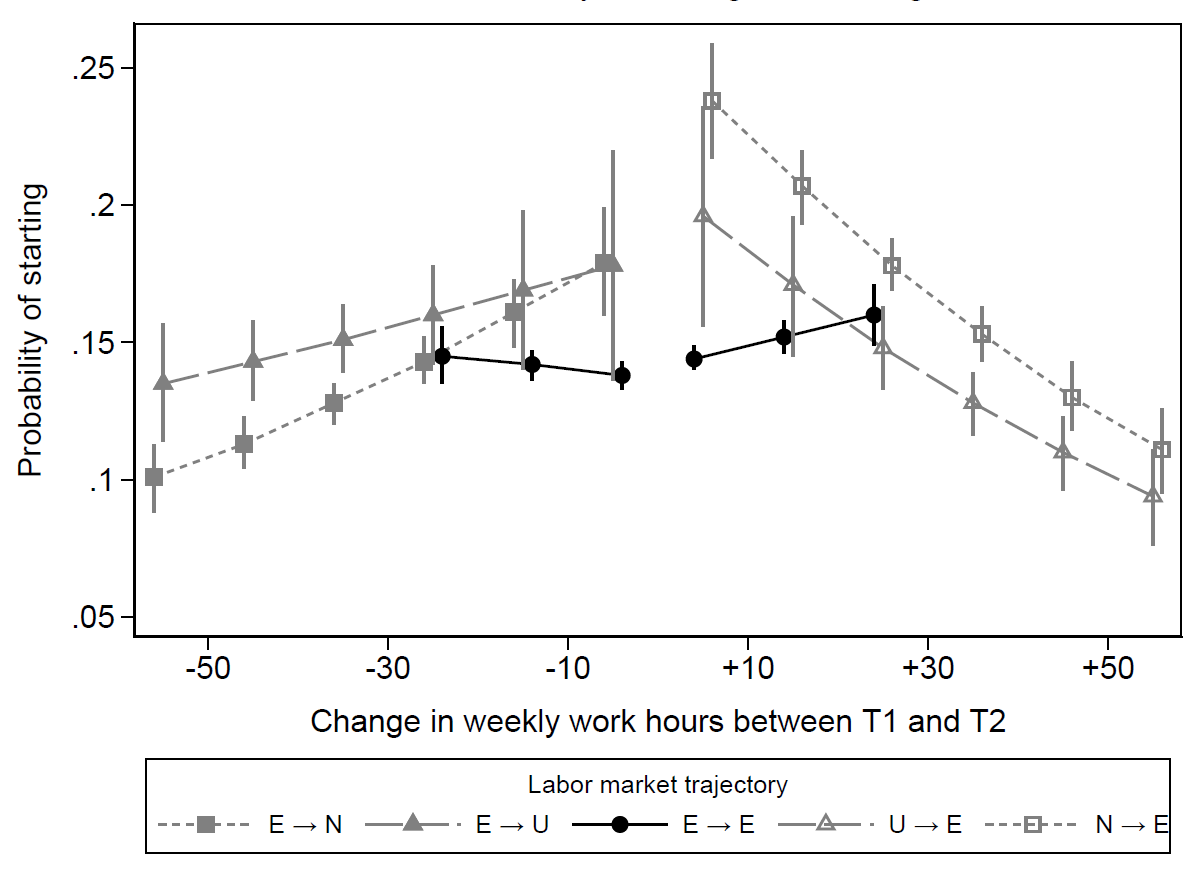

B. Probability of stopping volunteering

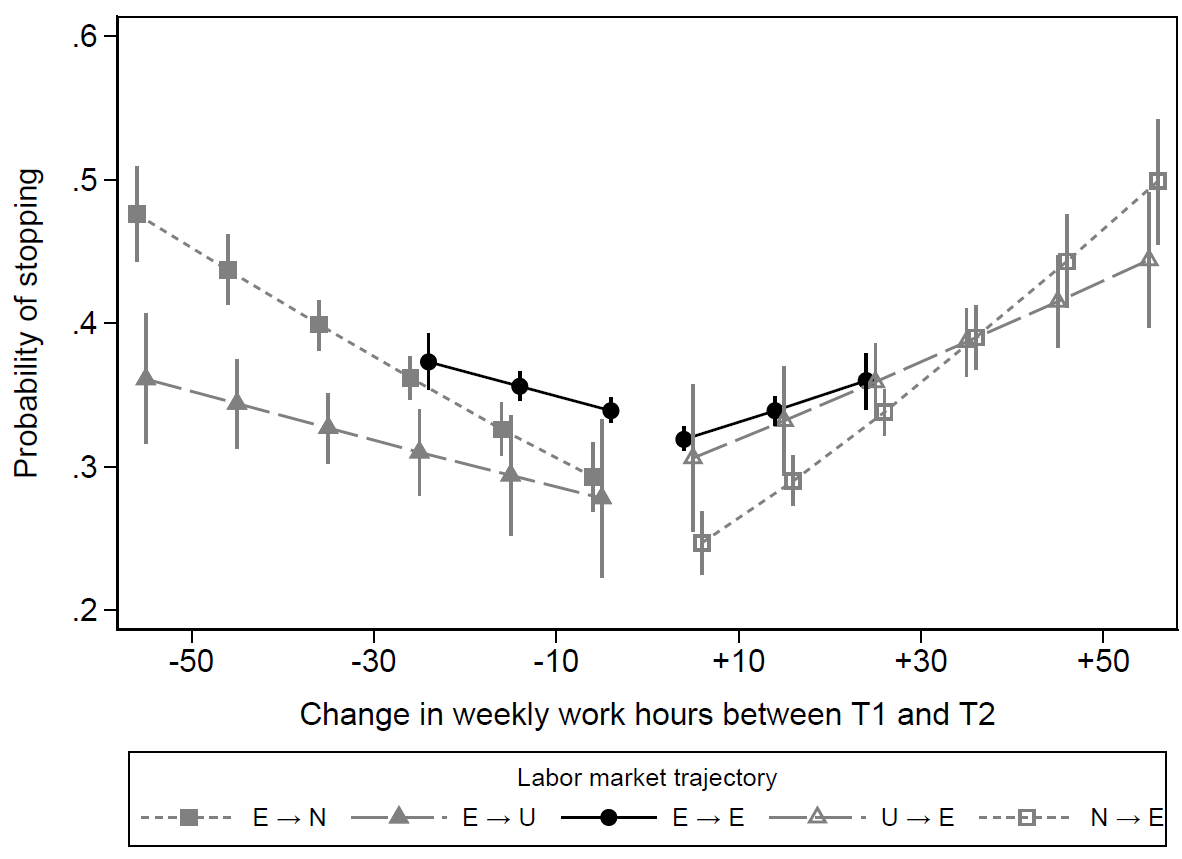

Note: The underlying models include all control variables mentioned in Section 3.2. Holding these constant at their actual value for each individual, we plot the average predicted probabilities across the sample of analysis. The error bars denote 95 percent confidence intervals. In the legends, "E" denotes employment, "U" unemployment, and "N" NILF status. The starting analyses comprise 216,559 individuals; the stopping analyses comprise 101,358 individuals. 